\title{
The Extract Method of Engineering Management Index Based on Rough Set
}

\author{
Chen $\mathrm{He}^{1,{ }^{*}}$ and Xueliang $\mathrm{Hou}^{2}$ \\ ${ }^{1} \mathrm{Xi}$ 'an architecture and technology university, Shaanxi province, China \\ ${ }^{2}$ Institute of engineering management, North China electric power university, Beijing, China \\ ${ }^{*}$ Corresponding author
}

\begin{abstract}
Index is very important for judging project implementation status or analyzes some problems in the process of engineering project management. The present method to determine index is mainly a professional empirical method and cannot fully meet the requirement of engineering project management. For the purpose of putting forward a scientific method, the paper first analyzes the path that how to obtain effective index based on diagnosis method of medicine and mechanical engineering. Moreover, with the guidance of rough set theory, a model to obtain characteristics and its parameters of problem phenomena is provided. According to the homeomorphous nature between index and parameter, the formula of their mapping relationships has been given. The results of this research are valuable theoretically and practically.
\end{abstract}

Keywords-problem phenomena; index; parameter; rough set

\section{INTRODUCTION}

During research on the actuality of china construction engineering management, a lot of problem phenomena in construction engineering projects had been gained through investigation. After analyze these problem phenomena, it can be known that these problem phenomenon can be divided into 22 categories 260 subcategories, which are 4 categories and 22 subcategories in decision-making stage, 6 categories and 65 subcategories in arranged stage, 7 categories and 144 subcategories in construction stage and 5 categories 29 subcategories in conclusion stage. Because these problems always bring some disadvantages to projects such as quality decline, schedule delay, cost increase, safety accidents or environments pollution, and sometimes even make engineering projects into an abnormal statue, how to find these problems in time in construction project management and solve them efficiently is paid more and more attention by project managers.

\section{INTRODUCTION OF OTHER SCIENCE DiAGNOSIS THOUGHT}

For solving these problems, lots of studies have been carried out, and some achievements have been gained. However, the methods put forward in these achievements cannot still solve above problems in practice efficiently, especially in how to find problems in time in the process of engineering implementation. Although there are many reasons, one of the main reasons is that these indexes to analyze problems have not been pertinence. An obvious behavior in these achievements is that different researchers often used different indexes to analyze a same problem in same condition and draw different result [1]. Obviously, this kind of mode to analyze and treat with engineering problems is disadvantage to improve engineering project management level.

In fact, as early as the late 1970s, the similar problems had also been appeared in the field of medicine and mechanical engineering. In order to put forward a kind of efficient method to solve practical problems, many researchers in the field of medicine and mechanical engineering analyzed a large amount of medical morbidity phenomena or mechanical failures, and put forward the medical or mechanical diagnosis method. Then, they tested it in practice and diagnose many problems in bodies or running equipment. Finally, it is proved by a large amount of practice examples that the efficient method to find problem is just to use some indexes that tightly correlate with corresponding problems refining some very valuable information which can reflect real actuality of problems. Seeing from the angle of science, the analysis of problems in engineering projects is very similar with the problem diagnosis in medicine and machine. Meanwhile, the similar system theory also points out that the method to solve problems is very similar when the management function and unit construction of research object are similar [2]. Thus, the diagnosis thought and method of medicine and mechanical engineering just provide a new idea for us to analyze problems in engineering projects.

\section{ChARACTERISTIC ANAlyses OF PROBlem PhenOMENA}

It According to the medicine and mechanical diagnosis theory, if project managers want to find problems in engineering implementation efficiently, diagnosis indexes corresponding with problems phenomena must be gained. Because these diagnosis indexes should be determined by their corresponding characteristics parameters, while these parameters should be gained from their corresponding characteristics, so, firstly, the most important work is how to gain these characteristics and their parameters of problem phenomena.

The set theory thinks that analysis of problems characteristic and parameter is just a mapping process that makes some propositions which are able to reflect the research object's information characteristics focus on a new variable. Because the mapping process includes combination of similar terms and many dimensions contrast of characteristic and phenomena, the process will be a transformation of decreasing dimension from high dimension space to low dimension space. 
For the transformation of decreasing dimension, now, there are many methods like fuzzy clustering, BP neural network or principal component analysis, but many research achievements have proved that these methods have stronger disturbance and fuzzy ascription for engineering problems [3]. However, rough set theory can express the core of problem characteristics by information reduction and set equivalence for the transformation problem[4], and also eliminate subjective disturbance during analyzing problems[5], so, the rough set theory can just be used to the analysis of problem's characteristic and parameter.

In information reduction, the rough set theory points out that information redundancy $f$ in problem phenomena can be eliminated by reduction relationship $F$. If express it by mathematical formula, that is $\operatorname{IND}(F)=\operatorname{IND}(F-\{f\})$.After reducing redundancy, all irreducible relation sets just become the core of $F$. If all problem phenomena $x_{t}$ in set $S$ can be distributed into sets $\{G X\}$, here, $G$ delegates four stages of engineering project, $M, N, O, P \in G, M, N, O, P$ is the subcategory of every stage , then, $\bigcup G X=\bigcup\left\{G x_{t}\right\}=\left\{M x_{t} \cup N x_{t} \cup O x_{t} \cup P x_{t}\right\} \in S$. Where, $t$ is the subcategory amount of problem phenomena. Meanwhile, it can be known according to the theory of rough set, if let $A$ be characteristic set of all problem phenomena $x_{t}$, let $B$ be parameter set, $C$ is a knowledge reduction of $\{G X\}$, then,

$$
\begin{gathered}
G C \in C(G A, G B \subseteq G C) \quad\{G f\} \in G X-G C \\
\{G f\} \notin \bigcap\{G C: G C \in R E D(G X)\}
\end{gathered}
$$

$$
\begin{gathered}
I N D(G X) \Rightarrow[G C: G A \in G C, G B \in G C]=I N D(G C) \\
G C \in G X-\{G f\} \subseteq G X\{G f\} \notin C O R E(G X) \\
\operatorname{CORE}(G X)_{F} \subseteq \bigcap\{C: C \in R E D(G X) \subseteq \cup G X\}
\end{gathered}
$$

$$
\begin{gathered}
\operatorname{CORE}(G A)_{F} \subseteq \bigcap\{A: A \in R E D(G A)\} \\
\operatorname{CORE}(G B)_{F} \subseteq \bigcap\{B: B \in R E D(G B) \subseteq \cup G A\}
\end{gathered}
$$

It can be seen from the analysis results that the cores of characters and parameters of problem phenomena can be gained by information reduction. Because this analysis process is able to be used for analysis of all problem phenomena, a model to gain characteristics and parameters of problem phenomena can be set up, that is,

$$
\operatorname{CORE}(G A)_{F} \subseteq \cap\{A: A \in \operatorname{RED}(G A)\} \Rightarrow \operatorname{CORE}(G A)_{F}=\left(\Lambda G_{X_{t}}\right)_{F}
$$

$$
\operatorname{CORE}(G B)_{F} \subseteq \bigcap\{B: B \in \operatorname{RED}(G B)\} \Rightarrow \operatorname{CORE}(G B)_{F}=[\cup G A]_{F}
$$

Thus, when analyzing some problem phenomena, all characteristics and their parameters corresponding with problem phenomena in engineering project can be gained by the model after making every research object transform into corresponding characteristic symbol.

\section{The Method to EXTRACt InDEX}

The set theory points out that index are homeomorphous with parameter [6]. If index is a set $D$, parameter is a set $B$, they must have same set potential and mapping relationships. So, it can be known from above theoretical analysis results of characteristics and parameters, parameters and indexes must exist following homeomorphous relationships. That is,

$$
\begin{gathered}
\left\{\cup M B_{t}\right\} \Rightarrow_{d f} \operatorname{dom}\left(F_{M}\right) \quad\left\{\cup N B_{t}\right\} \Rightarrow_{d f} \operatorname{dom}\left(F_{N}\right) \\
\left\{\cup O B_{t}\right\} \Rightarrow_{d f} \operatorname{dom}\left(F_{O}\right) \quad\left\{\cup P B_{t}\right\} \Rightarrow_{d f} \operatorname{dom}\left(F_{P}\right) \\
\because h: M B_{t} \longrightarrow^{i n j} M D_{t} \Rightarrow \operatorname{dom}\left(F_{M}\right) \longrightarrow^{i n j} \operatorname{ran}\left(F_{M}\right)
\end{gathered}
$$

$$
h: N B_{t} \stackrel{i n j}{\longrightarrow} N D_{t} \Rightarrow \operatorname{dom}\left(F_{N}\right) \stackrel{i n j}{\longrightarrow} \operatorname{ran}\left(F_{N}\right)
$$

$$
h: O B_{t} \stackrel{i n j}{\longrightarrow} O D_{t} \Rightarrow \operatorname{don}\left(F_{O}\right) \stackrel{i n j}{\longrightarrow} \operatorname{ran}\left(F_{O}\right)
$$

$$
h: P B_{t} \stackrel{i n j}{\longrightarrow} P D_{t} \Rightarrow \operatorname{dom}\left(F_{P}\right) \stackrel{i n j}{\longrightarrow} \operatorname{ran}\left(F_{P}\right)
$$

$$
\therefore \operatorname{ran}\left(F_{M}\right) \in\left[D_{M}\right]=\left\{\cup M D_{t}\right\}, \operatorname{ran}\left(F_{N}\right) \in\left[D_{N}\right]=\left\{\cup N D_{t}\right\}
$$

$$
\operatorname{ran}\left(F_{o}\right) \in\left[D_{0}\right]=\left\{\cup O D_{t}\right\}, \operatorname{ran}\left(F_{P}\right) \in\left[D_{P}\right]=\left\{\cup P D_{t}\right\}
$$

Obviously, the illation result shows that diagnosis indexes corresponding with parameters can be extracted if these problem phenomena's characteristics and their corresponding parameters have been gained in advance. However, it can also be known from the analysis process that lots of knowledge logic is needed in the analysis process. This means researchers must know well their professional knowledge, but also have 
abundant practical experiences. This is because the gaining of problem character mainly depends on theoretical description based on experience, while the gaining of characteristic parameter mainly depends on theoretical illation based on knowledge logic. Based on which, let characteristic parameters corresponding with problems transform into corresponding characteristic symbols, the corresponding indexes with these characteristic parameters can be extracted by above method. Now, take engineering quality problems in Tab.1 as an example, their indexes extracted by the above method are shown as following Tab.2. Of course, if there are many indexes when analyzing a research object, in order to manage and use indexes conveniently, they should be endued with corresponding codes according to the universal coding rule.

TABLE I. CHARACTERISTICS AND THEIR PARAMETERS OF ENGINEERING QUALITY PROBLEMS

\begin{tabular}{|c|c|c|c|c|}
\hline $\begin{array}{l}\text { Category of } \\
\text { problem }\end{array}$ & Code & $\begin{array}{l}\text { Phenomena } \\
\text { characteristic }\end{array}$ & $\begin{array}{l}\text { Parameter } \\
\text { code }\end{array}$ & Characteristic parameter \\
\hline \multirow{8}{*}{$\begin{array}{l}\text { Engineering } \\
\text { quality }\end{array}$} & \multirow{3}{*}{ CT11 } & \multirow{3}{*}{$\begin{array}{c}\text { Quality } \\
\text { management is } \\
\text { not in place }\end{array}$} & CP111 & quality goal \\
\hline & & & CP112 & $\begin{array}{l}\text { quality assurance } \\
\text { measures }\end{array}$ \\
\hline & & & CP113 & process supervision \\
\hline & \multirow{5}{*}{ CT12 } & \multirow{5}{*}{$\begin{array}{l}\text { Detection } \\
\text { analysis is not } \\
\text { rigorous }\end{array}$} & CP121 & quality assessment \\
\hline & & & CP122 & equipment installation \\
\hline & & & CP123 & function tests \\
\hline & & & CP124 & performance detection \\
\hline & & & CP125 & materials detection \\
\hline
\end{tabular}

TABLE II.DIAGNOSIS INDEXES OF ENGINEERING QUALITY PROBLEMS

\begin{tabular}{|c|c|l|l|l|}
\hline Category & Code & \multicolumn{1}{|c|}{ Diagnosis purpose } & \multicolumn{1}{|c|}{ Index } & $\begin{array}{l}\text { Index } \\
\text { code }\end{array}$ \\
\hline $\begin{array}{c}\text { Quality } \\
\text { management }\end{array}$ & IC11 & $\begin{array}{l}\text { Are all engineering qualities } \\
\text { objects established and } \\
\text { defined? }\end{array}$ & $\begin{array}{l}\text { Perfection } \\
\text { rate }\end{array}$ & IC111 \\
\cline { 3 - 5 } & $\begin{array}{l}\text { Are all quality measures } \\
\text { made? }\end{array}$ & $\begin{array}{l}\text { Completion } \\
\text { rate }\end{array}$ & IC112 \\
\cline { 3 - 5 } & $\begin{array}{l}\text { Are the process intendance } \\
\text { and control efficient? }\end{array}$ & $\begin{array}{l}\text { Availability } \\
\text { rate }\end{array}$ & IC113 \\
\hline \multirow{5}{*}{ Quality analysis } & IC12 & $\begin{array}{l}\text { Do the main body's qualities } \\
\text { meet standard? }\end{array}$ & $\begin{array}{l}\text { Accredited } \\
\text { rate }\end{array}$ & IC121 \\
\cline { 3 - 5 } & $\begin{array}{l}\text { Do the installation precisions } \\
\text { of equipments meet } \\
\text { standard? }\end{array}$ & $\begin{array}{l}\text { Accredited } \\
\text { rate }\end{array}$ & IC122 \\
\cline { 3 - 5 } & $\begin{array}{l}\text { Do the functions meet } \\
\text { preplanned request? }\end{array}$ & $\begin{array}{l}\text { Accredited } \\
\text { rate }\end{array}$ & IC123 \\
\hline & $\begin{array}{l}\text { Do the tests of equipments } \\
\text { capability meet standard? }\end{array}$ & $\begin{array}{l}\text { Accredited } \\
\text { rate }\end{array}$ & IC124 \\
\cline { 3 - 5 } & $\begin{array}{l}\text { Do the test results of } \\
\text { material meet standard? }\end{array}$ & $\begin{array}{l}\text { Accredited } \\
\text { rate }\end{array}$ & IC125 \\
\hline
\end{tabular}

\section{CONCLUSIONS}

For the problem that how to extract indexes scientifically, the research result shows rough set theory is a better and useable tool. Rough set theory not only can describe the research object's characteristics, but also the research object's parameters corresponding with their characteristics can also be gained. If make these parameters transform into corresponding characteristic symbols, then, the cores of characters and parameters of research objects can also be gained by information reduction. Based on which, indexes corresponding with parameters can just be extracted by the index models. So, rough set theory is an effective method to solve the problem.

The more important of all is that the method of index extraction only connects with known information, and the index extracting process must be carried out on the guidance of knowledge logic and mathematic illation. This means the method can eliminate individual subjectivity disturbance in the process of index extraction. Because the research result can also be used by other researchers analyzing how to gain research object's characteristics and their parameters, and how to extract their corresponding indexes in other fields, therefore, the research result has a very high value in theory and practice.

\section{ACKNOWLEDGMENT}

This study was supported by the national natural science foundation of China (Grant No. 71171081) and the natural science foundation of Beijing (Grant No. 9162014).

\section{REFERENCES}

[1] H. Liu. 2015. Evaluating Indexes of Risk Level in Construction Project by Fuzzy Matter-element Model. Energy Procedia Vol. 11, p. 112-116.

[2] S.N. Ju, Y.J. Jong, W.H. Yong, Y. N. Lee. 2014. Application of Similarity Theory to Load Capacity of Gearboxes. Journal of Mechanical Science and Technology Vol. 42 (2014), p. 204-209.

[3] P.A. Ana, B.R. Guajardo. 2016. A Fuzzy Clustering Procedure for Random Fuzzy Sets. Fuzzy Sets and Systems Vol.32, p. 1003-1007.

[4] J.V. Liang, R.L. Yu: Distance. 2017. A More Comprehensible Perspective For Measures in Rough Set Theory. Knowledge-Based Systems Vol.27, p. 231-236.

[5] X.P. Kang, D.Y. Li. 2014. Dependency Space, Closure System and Rough Set Theory. International Journal of Machine Learning and Cybernetics Vol.53, p. 252-261.

[6] B. Li, G.L. G.B. Xing, L.H. Li. 2015. Ship Electric Propulsion Simulation System Reliability Evaluation Based on Improved D-S Expert Weight Calculation Method. Mathematical Problems in Engineering Vol.37, p. 625-630. 